\title{
Cesário e uma Cara de seu Tempo (que não foi outra)
}

\author{
LUIS MAFFEI \\ Universidade Federal Fluminense
}

\begin{abstract}
RESUMO: CESÁRIO VERDE FOI, DECERTO, O PRIMEIRO AUTOR PORTUGUÊS A ENFRENTAR DE MANEIRA CENTRAL UM TÓPICO EXTREMAMENTE DIFÍCIL EM POESIA: O LUGAR DO POETA NUMA SOCIEDADE JÁ CONSOLIDADAMENTE BURGUESA. EM ALGUNS POEMAS, SOBRETUDO "CONTRARIEDADES" E "O SENTIMENTO DUM OCIDENTAL", CESÁRIO, ENQUANTO SE OBSERVAVA COMO POETA EXCLUÍDO, OBSERVAVA OUTROS EXCLUÍDOS DE SEU TEMPO, E REALIZOU UMA CRÍTICA MORDAZ E ATENTA AO CENÁRIO QUE SE LHE APRESENTAVA.
\end{abstract}

ABSTRACT: CESÁRIO VERDE WAS, CERTAINLY, THE FIRST PORTUGUESE AUTHOR TO FACE IN CENTRAL WAY AN EXTREMELY DIFFICULT TOPIC IN POETRY: THE PLACE OF THE POET IN A SOLID BOURGEOIS SOCIETY ALREADY . IN SOME POEMS, OVER ALL "CONTRARIEDADES" E "O SENTIMENTO DE UM OCIDENTAL", CESÁRIO, WHILE OBSERVES HIMSELF AS EXCLUDED POET, OBSERVES EXCLUDED OTHERS OF HIS TIME, AND CARRY OUT A SCATHING AND ATTENTIVE CRITICISM TO THE SCENERY THAT WAS PRESENTED TO HIM.

PALAVRAS-CHAVE: CESÁRIO VERDE; BURGUESIA; HISTÓRIA; TRABALHO; SOCIOLOGIA KEY WORDS: CESÁRIO VERDE; BOURGEOISIE; HISTORY; WORK; SOCIOLOGY 
firma Jorge Nóvoa: "Marx foi (...) à busca de uma síntese superadora e consciente entre esses dois extremos que foram o racionalismo e o romantismo" (NÓVOA, 2007, p. 256). Século XIX: sintetizar racionalismo e Romantismo foi tarefa a que se dedicaram diversos autores do Oitocentos português. Cesário Verde, sabe-se, terá ido bem adiante: foi ele um dos inventores do que se pode chamar de literatura moderna em Portugal, pois a "poética que subjaz à sua escrita (...) é, grosso modo, a que por todo o século XX tem prevalecido" (NAVA, 2004, p. 56), de acordo com Luís Miguel Nava. Não me darei o trabalho de apresentar o poeta, não nesta altura dos acontecimentos, é escusado. Apenas lançarei a proposta básica deste ensaio: Cesário realizou uma mui própria observação sociológica de seu tempo. Cesário pensava em poesia, mas era levado a pensar, a partir da poesia, em outras coisas. Mercado e trabalho, por exemplo. E temas afins a esse, a partir de Cesário, perpassam muita da poesia escrita a posteriori, o que corrobora a afirmação de Nava.

Uma estrofe fundamental de "Contrariedades": "Nas letras eu conheço um campo de manobras;/ Emprega-se a réclame, a intriga, o anúncio, a blague,/ E esta poesia pede um editor que pague/ Todas as minhas obras..." (VERDE, 1995, p. 60). Não é romântica a poesia de Cesário, nem sei se procura alguma síntese - penso, como é evidente, no comentário citado sobre Marx. Pensando ainda, cogito: há racionalismo em Cesário Verde? Há, apesar de tudo, algum romantismo? Se eu quiser considerar alguns autores que escreviam contemporaneamente a Cesário, lembrar-me-ei forçosamente de Eça, interessado numa crítica social de fito transformador. Pensarei também em Antero, autor de uma análise, o indispensável "Causas da decadência dos povos peninsulares nos últimos três séculos”, cuja perspicácia (e atualidade?) é espantosa. Perto desses dois imensos observadores da vida social e humana portuguesa, como faz Cesário o que chamei de mui própria observação sociológica de seu tempo?

Ao poeta interessava, antes de tudo, localizar-se em seu mundo, e, para isso, era necessário localizar seu mundo, refletindo sobre o homem dentro do mundo. Pensar no homem, poeticamente, solicita pensar em si mesmo - herança romântica? Será apenas Camilo Pessanha quem conseguirá relativizar o papel do eu em poesia portuguesa? E pensar em si mesmo significa pensar-se em articulação, jamais evasiva, com o meio - ruptura com certos romantismos e afinidade com certo Realismo? Terá sido Cesário o primeiro autor 
relevante do século XIX a se projetar globalmente sem deixar de ter em vista, angustiada e incontornavelmente, seu próprio lugar? São abrangentes demais essas suspeitas, deixo-as. Mas preciso voltar, não ainda à estrofe já citada, mas à abertura de "Contrariedades": "Eu hoje estou cruel frenético, exigente;/ Nem posso tolerar os livros mais bizarros./ Incrível! Já fumei três maços de cigarros/ Consecutivamente." (VERDE, 1995, p. 57).

Fala o eu, e fala de si. A situação, nesse poema que teve "Nevroses" como título, é de desajuste e a autocentralização leva o sujeito a um discurso que, em tese, poderia não interessar a quem quer que fosse. No entanto, o frenesi e o fumo são indícios de que uma catarse terá lugar, mas terá lugar também, a partir da terceira estrofe, um espelhamento: "Sentei-me à secretária. Ali defronte mora/ Uma infeliz, sem peito, os dois pulmões doentes;/ Sofre de falta de ar, morreram-lhe os parentes / E engoma para fora." (VERDE, 1995, p. 57). Talvez se possa pensar na Juliana d'O primo Basílio, mas com cuidado: mesmo que exista análogo espelhamento no romance queirosiano, isso se dará a partir de um narrador onisciente e bastante atento às oposições que quer construir, nomeadamente a que afasta e aproxima Juliana a Luiza. No caso do poema, não existe onisciência, existe observação, o mesmo que se dá em "O sentimento dum ocidental".

Poeta e uma "infeliz": há um mundo que leva o eu a uma crise e leva o outro a outra crise. Acabo de grafar um vocábulo importante para Marx, e cito um fragmento do Manifesto do Partido Comunista: "O sistema burguês tornou-se demasiado estreito para conter as riquezas criadas em seu seio. De que maneira consegue vencer essas crises?". O Manifesto é publicado pela primeira vez em 1848 e o poema de Cesário data de 1876. Não há a menor dúvida: vivia-se um mundo já solidamente burguês, e, se a burguesia, tempos antes, fora uma hipótese refrescante de oposição ao absolutismo, então já exercia um papel dizível pelo nome direita. Cesário refere-se a condições de trabalho e realiza uma flagrante crítica ao mundo burguês. Marx e Engels prosseguem sua reflexão: "De que maneira consegue a burguesia vencer" as "crises? De um lado, pela destruição violenta de grande quantidade de forças produtivas; de outro lado, pela conquista de novos mercados e pela exploração mais intensa dos antigos"; pensam os autores na conseqüência mais grave dessa prática: "A que leva isso? À preparação de crises mais intensas e destruidoras e à diminuição dos meios de evitá-las" (ENGELS \& MARX, 2006, p. 91). 
Sim, faz sentido, apesar de tudo, pensar na Juliana d'O primo Basílio, pois a personagem cesarina, assim como a queirosiana, já se encontra diante de um tipo de crise que não lha permite mudar as coisas revolucionariamente, tampouco mover-se pelas classes sociais. No romance, a empregada chantageia a patroa a fim de tornar-se, ainda que instavelmente, patroa, pois o jogo só pode ser de inversão se há, como há, imobilidade social. Uma das crises que o capitalismo aprecia gerar é a desigualdade social: do outro lado da janela acha-se uma "infeliz, sem peito, os dois pulmões doentes" que, não obstante, "engoma para fora". Gosto de observar a estrutura dos poemas de Cesário, especialmente "O sentimento dum ocidental" e "Contrariedades". No primeiro caso, as estrofes de quatro versos têm, cada uma, três versos de dez e um, que as encerra, de doze. Sendo o poema uma leitura aguda d'Os Lusíadas, o decassílabo não resiste a versos cuja medida permite ao sujeito dizer, por exemplo, o verso final da primeira estrofe: muitas coisas em Lisboa "Despertam-me um desejo absurdo de sofrer" (VERDE, 1995, p. 97). Assim, do decassílabo ao alexandrino, sem que nenhum se imponha como metro único.

No caso de "Contrariedades", os três primeiros versos de todas as quadras têm doze, mas os respectivos últimos têm seis sílabas métricas. É como se os alexandrinos não suportassem o difícil engenho que os rege e se vissem, nos momentos-chave das estrofes, cortados ao meio. O desabafo adverbial da primeira quadra, por exemplo, "Consecutivamente", não poderia obedecer ao modus alexandrino, tampouco a triste conclusão da terceira, a que apresenta a trabalhadora: "E engoma para fora”. Aliás, essa é outra informação fulcral acerca da personagem: seu trabalho não é para si mesma, cumpre demandas de outrem, pois é "para fora" que vão as roupas. Portanto, as peças de vestuário não pertencem à mulher vista através da janela, mas a quem pode pagar à mulher vista através da janela.

Parece-me de forte pertinência reler um dos grandes textos do século XX, Eros e civilização, para entender muito do que ainda se passa nas sociedades contemporâneas e também para pensar o Cesário que aqui me importa. Se a mulher "engoma para fora" apesar de sua doença física, é, na melhor das hipóteses, reduzido seu controle sobre o corpo que possui. É por situações como essa que Marcuse pôde observar que "durante os dias de trabalho", o homem existe "como instrumento de desempenho alienado; o resto do tempo está livre para si próprio" (MARCUSE, 1999, p. 59). Com o "resto do tempo", que faz a en- 
gomadeira? "Mantém-se a chá e pão! Antes entrar na cova./ Esvai-se; e todavia, à tarde, fracamente,/ Oiço-a cantarolar uma canção plangente/ Duma opereta nova!" (VERDE, 1995, p. 59). A trabalhadora não usufrui de seu corpo nem de seu intelecto, pois ela é subtraída de seu corpo doente e dos gozos estéticos que poderia ter para além da miserável “opereta nova”. Já que teimo em pensar no Eça d'O primo Basílio, ocorre-me que Luiza, produto de seu meio burguês, nada lê senão certos exemplares românticos.

Mas, sublinho, antes de ver a vizinha o poeta se vê e vê a vizinha apenas porque se vê num cenário específico. Devo voltar à ideia de crise, pois a citei num contexto marxiano e cabe tratar dela, sendo Cesário poeta de fins do século XIX, num contexto mallarmaico. O artigo "Crise de Vers" data de 1895, mais adiante no tempo que a produção poética de Cesário Verde. No entanto, há, de acordo com o poeta francês, uma crise intrínseca à poesia, e Cesário esteve "cruel, frenético, exigente". Afirma Marcos Siscar que "Crise de vers", "texto (...) em que Mallarmé reuniu vários elementos de sua reflexão a propósito do assunto", "em português é normalmente mencionado ou traduzido por "Crise do Verso"'. O poeta e ensaísta brasileiro prefere uma tradução como "Crise de Verso" ou "Crise de Versos", mesmo porque existe "um paralelo com 'crise de nerfs' (ataque de nervos)" (SISCAR, 2008, p. 211).

Portanto, "a crise de verso não designa uma interrupção ou um colapso histórico do verso, mas uma irritação do verso, dentro do verso, e a propósito dele". Já que quero traçar uma relação entre a crise proposta por Mallarmé e a enfrentada por Cesário, cito um pouco mais da reflexão de Siscar: "Logo no início do ensaio, Mallarmé se refere à morte de Victor Hugo como um acontecimento historicamente decisivo para a poesia (...). A morte do poeta", Hugo, "como que significaria a morte do próprio verso. Não do verso em geral (...), mas especificamente do verso alexandrino ou (...) de um certo uso do alexandrino, ancorado na tradição solene da rima e da métrica, que combinaria com brindes em recepções elegantes e com o aparato de festas cívicas" (SISCAR, 2008, p. 212).

Experimenta Cesário sua própria crise de vers? É claro, pois a transição dos alexandrinos a sua metade em cada uma das estrofes de "Contrariedades" aponta para uma forma um tanto irritada, que lida com situação também irritada, "cruel", frenética e "exigente", quase da ordem das "Nevroses". Mallarmé, ao localizar na morte de Hugo a morte "de um certo uso do ale- 
xandrino", pensa em solenidade e "festas cívicas". Não deixa de ser curioso que a magnífica leitura camoniana que Cesário intitula de "O sentimento dum ocidental" deva sua circunstância a uma festa cívica, o primeiro dia de Camões. No poema, alexandrinos, mas apenas no último verso de cada uma das estrofes: a festa cívica que foi o 10 de junho de 1880 não iludiu o poeta, bem pelo contrário. É em "Contrariedades", contudo, que aparece a palavra "alexandrinos", e num hexassílabo: "A adulação repugna aos sentimentos finos;/ Eu raramente falo aos nossos literatos,/ E apuro-me em lançar originais e exactos,/ Os meus alexandrinos...” (VERDE, 1995, p. 59): o sujeito encontrase num tempo em que se impõe, também relativa às letras, a noção de trabalho, o que me devolve à primeira estrofe que citei: "Nas letras eu conheço um campo de manobras;/ Emprega-se a réclame, a intriga, o anúncio, a blague,/ E esta poesia pede um editor que pague/ Todas as minhas obras...".

O século XIX assistiu à solidificação do que hoje conhecemos como mercado editorial e é, portanto, nesse século que o "campo de manobras" passa a ser item fundamental do jogo literário, ou melhor, do jogo de quem queira editar livros. Não perco de vista que a "engomadeira" canta uma "opereta nova", pois decerto não lhe chegam às mãos exemplares como os que Cesário jamais conseguiu editar - O livro de Cesário Verde, sabe-se, é edição póstuma, e o próprio poeta, após editar "O sentimento dum ocidental" num periódico portuense, reclama, numa carta a António de Macedo Papança: "Literariamente parece que Cesário Verde não existe” (apud FERREIRA, 1995, p. 7). É evidente que, havendo em Portugal um grave problema de educação (malgrado os esforços empreendidos, em texto e fora dele, por muitos intelectuais a partir do Romantismo), poucas chances teria a "engomadeira" de decodificar um exemplar cesarino; ainda que o conseguisse, talvez não passasse da mera decodificação.

O fato é que, numa dinâmica de mercado, o sujeito que se vê em seu tempo e em seu lugar vê-se incapaz de cumprir requisitos que lhe permitam ao menos editar, pois não encontra um "editor" que "pague" suas "obras". Está profundamente redimensionado o lugar do poeta e seu ofício nobre passa a ser trabalho, que precisa atender a exigências da sociedade capitalista. Assim, não obstante as tangências possíveis entre a crise cesarina e a mallarmaica, a crise de vers que achaca o poeta português tem, de fato, muito a ver com as crises burguesas que Marx e Engels detectam e acusam. Ou seja, não se trata, no caso de 
Cesário Verde, apenas de esgotamento ou de reflexão sobre a forma (diz Siscar que "o texto de Mallarmé (...) é muito menos um epitáfio para o verso do que um elogio do verso livre" (SISCAR, 2008, p. 213), e Cesário jamais lançou mão de versos livres), mas do enfrentamento doloroso de uma crise histórica e social, que obriga o poeta a uma particular mirada sociológica.

Em seu alvo, poeta e "engomadeira", num jogo de espelhos que os aproxima: ambos se encontram excluídos de um contexto que melhor poderia acomodá-los. No alvo dessa mirada estão também diversos outros componentes de um jogo social de que Cesário faz parte, mas num lugar problemático. Em "Contrariedades", por exemplo, em concomitância ao drama de sentir a si próprio e observar a "engomadeira", o poeta não deixa de perceber que "Deu meia-noite; e em paz pela calçada abaixo,/ Um sol-e-dó. Chovisca. O populacho/ Diverte-se na lama” (VERDE, 1995, p. 58). Em “O sentimento dum ocidental", diversos são os tipos sociais que o caminhante observa em Lisboa. Exemplos não faltam, cito apenas dois: "Voltam os calafates, aos magotes,/ De jaquetão ao ombro, enfarruscados, secos" (VERDE, 1995, p. 98); "E mais: as costureiras, as floristas/ Descem dos magasins, causam-me sobressaltos;/ Custa-lhes a elevar os seus pescoços altos/ E muitas delas são comparsas ou coristas" (VERDE, 1995, p. 101).

Passeia pela cidade o sujeito, entre a solidariedade e a repulsa, entre o presente e a história. Cesário, que enfrenta crise de vers distinta da de Mallarmé, será um passeador distinto de Baudelaire. Segundo Leyla Perrone-Moisés, "se o tema de Cesário é baudelairiano, sua postura diante da cidade e seus habitantes é diversa da de Baudelaire". Isso porque “o viandante que se 'embrenha' e 'erra' por Lisboa não é o poeta flâneur baudelairiano, individualista que se sente destacado da multidão na qualidade de dândi, de 'herói' ou de 'esgrimista', avatares ainda românticos do poeta sem aura" (PERRONE-MOISÉS). Assim, se há romantismo em Cesário Verde, será subalterno e de discreta ação, pois a aura já está perdida há muito e a solidariedade cesarina não advém de qualquer viés romântico, mas de uma ácida observação de seu cenário.

E de sua história: são diversas as remissões a' Os Lusíadas feitas em 'O sentimento dum ocidental", poema editado numa data forjada com o intuito de tornar Camões, definitivamente, um herói nacional capaz de suprir lacunas severas de autoestima - num "contexto", sublinha Jorge Fernandes da Silveira, "às portas do Ultimatum” (SILVEIRA, 2003, p. 155). Não poderia ser tão 
Mallarmé nem tão Baudelaire Cesário Verde, pois seu poema, ainda segundo Jorge, proclama a "falência do rio-mar-oceano como via única para a história e ficção portuguesa" (SILVEIRA, 2003, p. 163) e desmonta o lugar torpe em que se pretendia colocar um imenso poeta do século XVI, destinado a ter função nada poética. Para tal desmonte, são muito oportunos versos como "Mas, num recinto público e vulgar,/ Com bancos de namoro e exíguas pimenteiras, / Brônzeo, monumental, de proporções guerreiras,/ Um épico de outrora ascende, num pilar!" (VERDE, 1995, p. 100).

O arguto espectador de seu tempo, o autor que "literariamente" "não existe", vai bastante além na detecção da decadência, mais que isso, na percepção de uma sociedade periférica e, portanto, burguesamente distinta de qualquer França. No Portugal de fins de século XIX, um sintagma como "As burguesinhas do Catolicismo" (VERDE, 1995, p. 101) é mais possível que em muitos outros lugares, pois, nesse pedaço difícil da Europa, a imbricação que o verso denuncia não é discreta. O poeta que se vê no mundo e vê seu mundo, trabalhando uma intensa articulação entre o eu e o que o entorna e, nalguma medida, enforma, convida Os Lusiadas em dois momentos-chave de seu triste passeio por Lisboa a fim de dizer algo profundamente social.

Primeiro caso: "Luta Camões no Sul, salvando um livro a nado!/ Singram soberbas naus que eu não verei jamais!". Estrofe seguinte: "E o fim da tarde inspira-me, incomoda!/ De um couraçado inglês vogam os escaleres;/ E em terra num tinir de louças e talheres/ Flamejam, ao jantar, alguns hotéis da moda" (VERDE, 1995, p. 98). Camões, referência gloriosa em poemas e simbologia. Seu mítico nado deve-se ao naufrágio de certa nau onde se encontrava; tendo que optar entre salvar Os Lusíadas ou a amante, salvo é o livro - trata-se de um mito, o que dá ainda mais força ao caso. Mas as "soberbas naus" nunca serão vistas por Cesário e não consta que ele tivesse qualquer problema de visão. Camões o tinha e, ainda assim, não apenas as viu, mas nelas navegou. $\mathrm{O}$ drama efetivo desses versos, relacionados diretamente à situação sócio-econômica de um país que não é o de Baudelaire e Mallarmé, deve-se ao fato de as "naus", "soberbas" e sumidas, terem como material compositivo a madeira, enquanto o "couraçado" e os "talheres" são feitos do mais resistente e up to date metal.

O "couraçado", claro, é "inglês", o ultimatum viria logo e a amargura do poeta em relação à Inglaterra, dita ao maldizer sua cidade, possuidora "duma 
cor monótona e londrina" (VERDE, 1995, p. 97), já fora dita em outro poema, "Deslumbramentos": "Milady, é perigoso contemplá-la,/ Quando passa aromática e normal,/ Com seu tipo tão nobre e tão de sala,/ Com seus gestos de neve e de metal" (VERDE, 1995, p. 35). Se em Cesário Verde a "temática erótica tinha (...) um objetivo provocador, que ia de par com a temática política" (PERRONE-MOISÉS), de acordo com Leyla Perrone-Moisés, "Milady" é mais que mera figura feminina a despertar enleios no sujeito: "Milady" é personagem política, tanto que o "metal" que compõe o "couraçado" compõe também os "gestos" da mulher.

Há, no final de "Deslumbramentos", uma revolução: "E um dia, ó flor do Luxo, nas estradas,/ Sob o cetim do Azul e as andorinhas,/ Eu hei-de ver errar, alucinadas,/ E arrastando farrapos - as rainhas!" (VERDE, 1995, p. 37). "A ele", Cesário, "se deve a expressão poética superior da pequenaburguesia lisboeta irreligiosa e republicana do tempo" (SARAIVA \& LOPES. 1996, p. 925), afirmam Saraiva e Lopes; "Que o homem Cesário fosse liberal, republicano e virtualmente socialista, está fora de dúvida. Entretanto, podese discutir até que ponto a sensibilidade social de Cesário, por mais autêntica e simpática que seja, é revolucionária” (PERRONE-MOISÉS), afirma Leyla Perrone-Moisés. Pode-se, com efeito. O que me provoca diretamente não é o virtual socialismo de Cesário, tampouco sua faceta pequeno-burguesa "irreligiosa e republicana". O que muito me provoca é verificar como esse poeta lidou com as transformações de seu tempo sobre o próprio discurso poético, e qual é o discurso poético resultante. Disso venho tentando dar conta, e tentarei mais um bocadinho.

Os versos seguintes a "Flamejam, ao jantar, alguns hotéis da moda" são: "Num trem de praça arengam dois dentistas;/ Um trôpego arlequim braceja numas andas" (VERDE, 1995, p. 98). Agora sim o fecho de ouro do que chamei de primeiro caso: se a madeira remete a "soberbas naus" e a Camões, enxergá-la a sustentar um "trôpego arlequim" diz muito. O caminho é do passado ao presente, do poeta ao palhaço, do nado que salva o livro a um movimento semelhante ao nado que nem nado logra ser. Mas é um segundo caso o que mais explora uma realidade de pobreza e faz com que se encontrem, metaforicamente, a exclusão que vitima muito da população e a que achaca o próprio poeta. Segundo caso: "Dó da miséria!... Compaixão de mim!.../ E, nas esquinas, calvo, eterno, sem repouso,/ Pede-me sempre esmola um ho- 
menzinho idoso,/ Meu velho professor nas aulas de latim!" (VERDE, 1995, p. 103). Não posso deixar de citar a expressão que abre a estrofe anterior, "Mas tudo cansa!", tampouco seu penúltimo verso: "Da solidão regouga um cauteleiro rouco" (VERDE, 1995, p. 103).

N'Os Lusíadas, o cansaço e a rouquidão do poeta aparecem no Canto X: "No mais, Musa, no mais, que a Lira tenho/ Destemperada e a voz enrouquecida,/ E não do canto, mas de ver que venho/ Cantar a gente surda e endurecida" (Lus, X, 145, 1-4). Cabe supor que, além do deslocamento da madeira, das "naus" ao "trôpego arlequim", desloca-se a rouquidão do poeta a um vendedor de loterias? Seguramente, pois os versos seguintes da estrofe camoniana são: "O favor com que mais se acende o engenho/ Não no dá a pátria, não, que está metida/ No gosto da cobiça e da rudeza/ Dhua austera, apagada e vil tristeza" (Lus, X, 145, 5-8). Ou seja, alguns dos versos que mais diretamente falam de prêmio - "favor" diz de uma recompensa, mais de audição que qualquer outra, à tarefa do canto - são postos em atualização por um prêmio meramente financeiro e baseado no acaso, não no merecimento. Cesário, como Camões, percebeu a injustiça que se lhe impôs e, assim como o poeta d'Os Lusíadas, esbravejou: "Independente! Só por isso os jornalistas/ Me negam as colunas" (VERDE, 1995, p. 58), leio em "Contrariedades".

E o professor de latim? Não há metáfora mais pungente para pobreza no poema. A língua é o espaço por onde trafegam as obras dos poetas, quaisquer que sejam, e também a motivação final de Vênus no épico camoniano: ajuda a deusa os navegantes portugueses, entre outras razões, em virtude da "língua, na qual, quando imagina,/ Com pouca corrupção crê que é a Latina” (Lus, I, 33, 7-8). E no tempo de Cesário? O latim como metáfora de um idioma modelar e original, talvez até como metáfora de uma identidade portuguesa construtível apenas nas letras, pede "esmola" "nas esquinas". E o poeta? O poeta escreve nessa língua possível e própria, e, em rigor, trabalha. Marcuse, outra vez: "Desde o despertar da consciência de liberdade, não existe uma só obra de arte que não revele (...) a negação da não-liberdade” (MARCUSE, 1999, p. 135).

Refletir sobre a posição de Cesário em seu tempo porventura se torne bastante profícuo a partir desse comentário de Marcuse. Mesmo submetido a diversas restrições, muitas delas oriundas de uma realidade que não tem que ver inerentemente com a literária, não é absurdo dizer que Cesário nega a "nãoliberdade", tanto na dicção política de sua obra como no próprio ato de realizá- 
la. A estrofe final de "Contrariedades", não sem alguma ironia mas com muito poder de observação do mundo, redimensiona o espelho que põe frente a frente, janela a janela, poeta e "engomadeira": "E estou melhor; passou-me a cólera. $\mathrm{E}$ a vizinha?/ A pobre engomadeira ir-se-á deitar sem ceia?/ Vejo-lhe luz no quarto. Inda trabalha. É feia.../ Que mundo! Coitadinha!” (VERDE, 1995, p. 60). Se Marx, de acordo com Jorge Nóvoa, "foi (...) à busca de uma síntese superadora e consciente entre esses dois extremos que foram o racionalismo e o romantismo", Cesário, pois mais que buscasse, teria a maior dificuldade em forjar alguma síntese: “Que mundo!”, diz o poeta. Fosse dona de um pensamento menos suprimido, interjeição idêntica poderia fazer a "engomadeira".

\section{Referências Bibliográficas}

CAMÕES, Luís de. Os Lusíadas. Org. Emanuel Paulo Ramos. Porto: Porto editora, 1978.

ENGELS, Friedrich \& MARX, Karl Heinrich. Manifesto do Partido Comunista. 10. ed. São Paulo: Global, 2006.

FERREIRA, Maria Ema Tarracha. Introdução. In VERDE, Cesário. O livro de Cesário Verde. Lisboa: Ulisseia, 1995, p. 7-29.

MARCUSE, Herbert. Eros e civilização - uma interpretação filosófica do pensamento de Freud. 8. ed. Trad. Álvaro Cabral. Rio de Janeiro: LTC, 1999.

NAVA, Luís Miguel. Sobre Cesário Verde. In --- Ensaios reunidos. Lisboa: Assírio \& Alvim, 2004, p. 55-56.

NÓVOA, Jorge. Para a reconstrução do paradigma da história: uma frente da razão?. In NÓVOA, Jorge (org.). Incontornável Marx. Salvador: EDUFBA/ São Paulo: Editora UNESP, 2007, p. 251-315.

PERRONE-MOISÉS, Leyla. “Cesário Verde: um 'astro sem atmosfera'?”. http:// www.geocities.com/ail_br/ail.html. Acesso: 08/07/2009.

SARAIVA, António Jose \& LOPES, Óscar. História da literatura portuguesa. 17. ed. Porto: Porto editora, 1996.

SILVEIRA, Jorge Fernandes da. Cesário, duas ou três coisas. In --- Verso com verso. Coimbra: Angelus Novus, 2003, p. 153-166.

SISCAR, Marcos. Poetas à beira de uma crise de versos. In PEDROSA, Célia \& ALVES, Ida. Subjetividades em devir - estudos de poesia moderna e contemporânea. Rio de Janeiro: 7Letras, 2008, p. 209-218.

VERDE, Cesário. O livro de Cesário Verde. Lisboa: Ulisseia, 1995. 